\title{
An Ontology-Based Knowledge Modelling for Sustainable Entrepreneurship Domain
}

\author{
Agnieszka Konys \\ West-Pomeranian University of Technology in Szczecin, Faculty of Computer Science and Information \\ Technology \\ 49 Żołnierska Street, 71-210 Szczecin, Poland \\ akonys@zut.edu.pl
}

\begin{abstract}
Sustainable entrepreneurship (SE) focuses on entrepreneurial activities taking into account environmental and social issues, not only by paying attention to economic issues. While the concept of SE is a prominent stream for modern entrepreneurship, the following questions arise: how enterprises can run a business and implement Sustainable Development Goals (SDG) and which factors can support or constrain SE? Research on SE suggests that that identifying and implementing sustainable development opportunity is more complex for the entrepreneur than the recognition of non-sustainable opportunity. Therefore this article contributes to the advancement of sustainable entrepreneurship research by offering an ontology-based approach collecting factors from the current literature review and incorporating different lines of research that can influence further sustainable entrepreneurial strategies. The applied research methodology exploits a previously elaborated bibliometric analysis which included a systematic literature review conducted using the PRISMA methodology. The condensed immense amount of bibliometric information and further co-occurrence analysis of keywords determining SE factors was a basis for constructing ontology-based model. This model offers a classification schema of sustainable entrepreneurship factors as well as a tool performing knowledge from being machine-readable to machineunderstandable.
\end{abstract}

\section{Introduction}

The concept of sustainable development currently plays an unquestionable role, covering various aspects of everyday life or business activities [1], [2]. Sustainable development implies on various areas from solar and wind energy systems, sustainable manufacturing [3], to sustainable business activities [4]. While sustainable development consists in satisfying present needs without compromising future generations growth [5], and requires simultaneous consideration of social, economic and environmental aspects [4], sustainable entrepreneurship (SE) focuses on entrepreneurial activities taking into account environmental and social issues, not only by paying attention to economic issues [1], [6].

Research on sustainable entrepreneurship suggests that the recognition and implementation of sustainable development opportunities are more complex for the entrepreneur than the recognition of non-sustainable opportunities [7], [8]. Therefore, the main research question is what kind of factors should be used in a particular decision situation?

Moreover, rapid changes and market globalization as well as technology advances force enterprises to adapt new enterprise models/solutions to face future digital enterprise needs. Against this background, it can be assumed that entrepreneurs creating, perceiving and using sustainable opportunities need support for successful innovation and entrepreneurial activities [9]. Therefore, it is critically important for entrepreneurs to have a dedicated solution to systematically facilitate the development of SE [6], [9]. This research aims to cover this gap offering a classification schema of sustainable entrepreneurship factors as well as a tool performing knowledge from being machine-readable to machine-understandable.

This article presents a knowledge-based approach to linking sustainable enterprise factors with the contribution of knowledge management. Accumulating knowledge and developing a shared knowledge base in the form of enterprise ontology dedicated to SE domain needs to be understood as a spiral process comprising the assessment of created knowledge, contextualizing shared knowledge [6], [8] and updating the knowledge base by applying it. As a result, the integrated modelling platform in a form of an ontology enables getting transparency about existing factors, abilities and relations and fitting sustainable-oriented strategies to a given enterprise. The proposed ontology-based approach will support the analysis, 
collection, ordering and sharing of the most influential factors and skills, as well as the relationships between them that are relevant to ensuring an appropriate level of enterprise sustainability.

The applied research methodology exploits a previously elaborated bibliometric analysis which included a systematic literature review conducted using the PRISMA methodology. The condensed immense amount of bibliometric information and further cooccurrence analysis of keywords determining SE factors aims to construct ontology-based model and provide conceptual guideline containing a full set of factors in a form of knowledge granules which should be used in a particular decision situation. The arising network exploiting the proposed ontology will provide the extension of the multi-perspective modelling approach for sustainable entrepreneurial value creation to increase sustainability development [10]-[12]. As a result, it can offer the common information backbone for further communication, collaboration and adaptation of sustainable strategies within the network by providing transparency and an integrated core of information of factors and abilities.

The paper is structured as follows: Section 2 presents literature overview of enterprise modelling and knowledge engineering aspects for SE and conceptual assumptions for building a framework for modelling SE domains. In section 3, an ontology-based attempt to modelling and integrating diverse aspects of $\mathrm{SE}$ is provided. Section 4 concludes the paper, wrapping up the research outcomes as well as describing limitations and putting the research findings in the context of future works.

\section{Enterprise modelling and knowledge engineering aspects for $\mathrm{SE}$}

\subsection{The concept of $\mathrm{SE}$}

There are many forms of conducting business/entrepreneurship. The literature proposes the categorization of field of entrepreneurship into several fields: social entrepreneurship, corporate social entrepreneurship, economic entrepreneurship and environmental entrepreneurship [1], [4], [6]. Briefly introducing these concepts, corporate social responsibility include references to ethical behavior related to the environment, society, and the economy [5], [7], whereas corporate social entrepreneurship is a process focused on enabling business to develop advanced and powerful forms of corporate social responsibility [6], [7]. The social entrepreneurship strongly refers to innovation activities with a social purpose in either the private or nonprofit sector or across both [5], whereas the environmental (green) entrepreneurship focuses on individual green orientation to models of entrepreneurial intention to increase their explanatory power [3].

Nowadays increased global competition is pushing enterprises to become more sustainable in the economic, environmental and social aspects [10], [13], [14]. In opposite to the traditional entrepreneurship, sustainable entrepreneurship considers additional factors, bringing the supplementary potential both for environment and the society [3]. In general, the aim of sustainable entrepreneurship is to highlight the important role of entrepreneurs in developing noneconomic gains to society [1], [15] and to provide comprehensive corporate social responsibility by balancing economic health, social equity and environmental resilience through their entrepreneurial behavior [13], [16], [17]. Sustainability-related entrepreneurship gives priority to the three main pillars of sustainable development: social, environmental and economic. This mainly distinguishes it from other forms of entrepreneurship that prioritize selective pillars.

\subsection{Various aspects of enterprise modelling}

Nowadays, enterprise models have proven necessary to support enterprise integration and interoperability. Continuous development, as well as the need for interoperability between different enterprise systems, brings new models in the form of ontological representations to capture more semantic and knowledge aspects of the structure, behavior and organization of the enterprise. These models take the form of enterprise ontology or also use ontology-based architecture. They are used in the form of frameworks as well as models and supporting tools for an integrated enterprise-wide decision-making process or ready-made solutions in the form of dedicated ontologies for integrated environmental assessment of technologies and processes or discovering the possibilities of enterprise modeling. Such solutions based on knowledge engineering for enterprise modeling effectively cope with the dynamically changing business environment.

The analysis of literature provides many research works [7], [11]-[13], [18]-[23], concerning ontologybased enterprise modelling. In work [7] the Authors presented a scenario that emerging stream seems to be a combination of enterprise modelling and knowledge management aimed to develop reference and reusable core manufacturing enterprise ontologies and behavior representations as required by the smart, sensing and sustainable (S3) enterprises of tomorrow [7], [19]. Further, in work [13], the Authors proposed an 
ontological framework which developed as the technology for information and knowledge models sharing for the environmental assessment of the enterprise. Then, ontological framework for enterprisewide integrated decision-making at operational level was presented by [13]. The applicability of an ontology was also introduced by [21], [24], offering supply chain ontology. Then, the application of knowledge representation to environmental issues was shown by [22] who presented a framework for expert knowledge sharing and discovery for integrated environmental assessment of technologies and processes associated with industrial ecology. In work [23] the Authors discovered capabilities of an enterprise modelling technique aimed to support an integrated handling of network configuration and sustainability management in a fast and efficient manner.

Summarizing, enterprise models must be managed appropriately to enable reuse knowledge assets. However, the knowledge must be organized to be locatable and understandable, what can be providing by EM, with the result that the knowledge is isomorphic to the enterprise itself [25]. In fact of that the proposed solution, as a form of an enterprise model, must be adaptive to be effective in the future, it should make appropriate usage of knowledge management elements can significant advances in the long-term sustainability for a given enterprise [16], [25]-[28]. Thus, the preferable approach requires a holistic view for the factors of SE, distributing intelligent approach to perform analysis, scenarios/strategies and decision-making (both in the real and digital worlds). The proposed ontology can be connected with various IT systems, being the basis for a new generation of sustainable (including green) enterprises. Ontology-based approach allows access to interconnected data that is dynamically scalable. In a globally connected economy, enterprises cannot achieve environmental, social/ethical or economic sustainability of any object (physical or virtual) without achieving ubiquitous ability of the objects and their creators and users to exchange and understand shared information and knowledge [18], [19]. Regarding these issues, reference ontology represents patterns, factors and partial strategies/scenarios which can be adapted by a given enterprise [19].

\subsection{Possibilities of using ontology in the SE domain}

Whereas an ontology is defined as formal, explicit specification of a shared conceptualization [29] and it describes the basic terms and relations comprising the vocabulary of a topic area as well as the rules for combining terms and relations to define extensions to the vocabulary [29], enterprise ontologies are focused on the domain or application level [10], which can in turn be specialized, and combined, into application ontologies [12], intended for structuring of enterprise information [30]. Generally, the aim of enterprise ontologies is to support structuring of enterprise information and knowledge management [10], [31]. Due to the fact that enterprise ontologies are application ontologies within enterprises for structuring of information [10], [30]-[32], they aim to provide a common structure for data collection by offering a collection of terms and definitions relevant to business enterprises [30], [33]. The extended information is included in section 2.2. (Usage of knowledge engineering for sustainable value creation) in related supplementary file: Extended Appendix and Data for Ontology-based Model for Sustainable Entrepreneurship [34].

Ontology-based solutions both in the form of Enterprise Ontology (EO) and Enterprise Architecture (EA) ontology are suggested and also successfully applied in many works [11], [20], [24], [33], [35]. The terms Enterprise Ontology and Enterprise Architecture currently belong to the standard vocabulary to designing and (re) engineering enterprises [11], [19], [20], [33], thereby exploiting modern information and communication technologies for innovating sustainable products and services [11], [36] as well as for optimizing operational performance [30]. The scope of $\mathrm{EO}$ is to ensure in particular acquisition, representation, and manipulation of enterprise knowledge [10], proposing a consistent core of basic concepts and language constructs [32]. Moreover, EO philosophy intended to structure and to organize libraries of knowledge [11], [20], as well as explained the rationale, inputs and outputs of the Enterprise Tool Set modules.

The main goal of solutions based on ontologybased enterprise architecture or enterprise ontology as forms of enterprise modeling is to design and build a modern network enterprise as an open, sophisticated holistic system. The use of an integrated modeling platform in the form of an ontology enables catching transparency on existing factors as well as the use of abilities and relationships through individual contextual views of sustainability assessment and sustainable development strategies tailored to the enterprise.

\subsection{A conceptual framework for SE domain modelling}

A need to have real-time data and providing applications with information and knowledge from diverse contexts to make right decisions for sustainable 
enterprises operations [1] seems to be one of the crucial elements deciding of competitive advantage. Thus, in modern sustainable enterprise, sustainable decision making requires effective knowledge management [16]. Due to the fact that the quality of decisions depends upon their being based upon relevant knowledge [13], [16], knowledge management has seen to be central to sustainable product and process innovation and improvement [6], [16], as well as to executive decision-making [13], and to organizational adaptation for sustainable strategies [2]. As a result, a synergistic combination of knowledge management and enterprise modelling forms a cycle of improvement and development leads to organizational excellence [18], [19], [25], [37].

To show the relationships between individual concepts, a conceptual framework was created in Fig. 1. This framework yields the general schema of connections and influences between considered concepts. It consists of the following elements: Social, environmental and economic factors and entrepreneurship, which makes the company sustainable as a result. All these factors have been collected in an ontology dedicated to sustainable entrepreneurship. In turn, knowledge management, enterprise modeling and knowledge engineering are elementary components responsible for providing functionality and mechanisms for the ontology of a sustainable enterprise.

The goal of the framework is to provide an overview of the considered problem of knowledge management for a sustainable enterprise. The created framework presents the genesis and impact of conditions for building a sustainable enterprise, as well as, it shows a combination of knowledge management forms and modelling the enterprise as complementary concepts. The result is the creation of the ontology for $\mathrm{SE}$ as a solution involving the use of modern forms of enterprise modelling based on knowledge management.

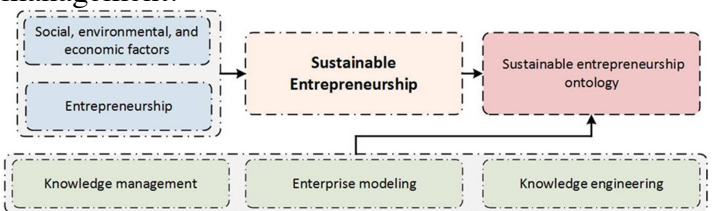

Fig. 1. A conceptual framework for SE domain modelling.

The result of modelling is stored in the knowledge base and is the basis for further learning. It may support the process the formation of enterprise as a sort of sustainable activities. The objective of ontologybased approach dedicated to SE domain is the design and creation of modern knowledge base as an open sophisticated holistic system by modeling and integrating its factors, abilities and organization structures in a one system, publicity available.

\section{An ontology-based attempt to modelling and integrating diverse aspects of SE}

Ontologies proved to be very useful tool in various research domains and research fields. The knowledge base presented in this article is a formal and practical basement towards handling intelligence knowledge and is an extension of IT systems to autonomous intelligent information systems. It is the postulated direction in many research works to extend information systems towards the construction of intelligent automatic solutions processing external knowledge instead of data information collected in organization. Hence the goal of this research is to conceptualize the process of externalization knowledge by integrating diverse aspects of SE, which is demonstrated through the enterprise ontology model in this paper.

\subsection{Methodology for ontology development}

Due to the fact that the ontology aims to be useful for sustainable enterprises, the enterprise ontology construction methodology is adapted. The purpose of constructed ontology is presented in related supplementary file: Extended Appendix and Data for Ontology-based Model for Sustainable Entrepreneurship Domain [34] in section 3.1. It contains the four main phases: capture - development of the informal ontology (see: 3.1.1. in the document referred above), followed by coding - development of the formal ontology (3.1.2.), integrating (3.1.3.) and documentation (3.1.5.). The first phase is aimed to identify purpose of the ontology and its potential users. In the second phase the building of the ontology itself takes place, in particular including the following parts: capture (identification of key concepts and relationships and defining terms), coding (formalization using ontology standard of description) and integrating (reuse and integration with other ontologies). Then the third phase of the evaluation allows checking the consistency and correctness of the ontology, as well as the improvement of the ontology in relation to the previously defined goal and scope of the ontology. Then, at the documentation phase, the ontology should be documented. The detailed phases' description is provided in related supplementary file: in section 3.1. Ontology construction process, placed in Extended Appendix and Data for Ontology-based Model for Sustainable Entrepreneurship Domain [34]. Fig. 2 shows the general schema of enterprise ontology 
construction process and actions related to knowledge engineering.

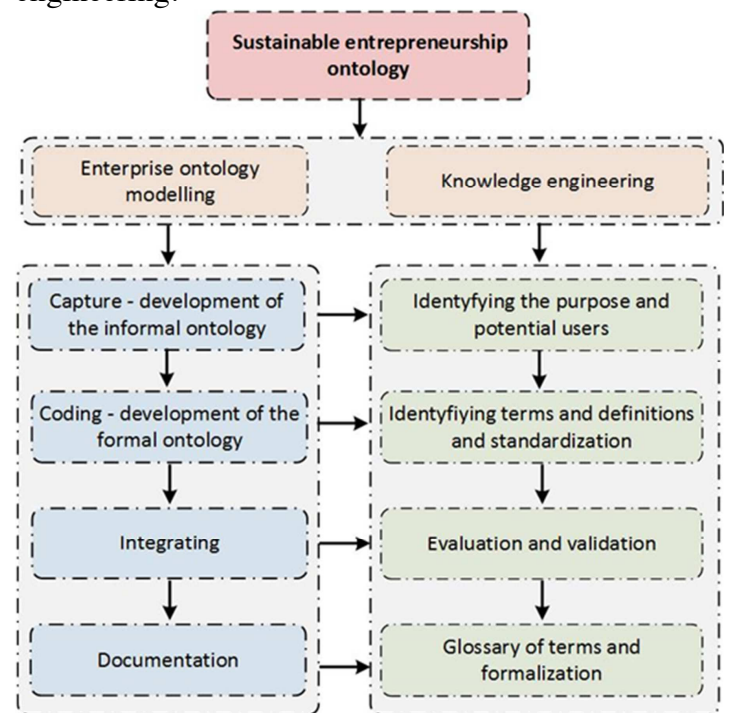

Fig. 2. The general schema of enterprise ontology construction process.

\subsection{Data collection}

The proposed ontology covers the domain of SE in a form of selected factors and provides a description of EO as a collection of terms and definitions relevant to business enterprises [7], [8]. The ontology was developed also on base of in-depth analysis of available literature presented in [38]. The applied research methodology exploits a previously elaborated bibliometric analysis which included a systematic literature review which was conducted using the PRISMA methodology. It allowed to retrieve ad condense the immense amount of bibliographic information and its performance in co-occurrence analysis of keywords determining SE factors and detailed different forms of distribution analysis. The dataset was built on base of Scopus database. The process of searching documents related to sustainable entrepreneurship from the Scopus database ended with the identification of 279 sources from 2002 to 2019 based on pre-defined query as follows: (TITLE-ABSKEY ("sustainable entrepreneurship"). The set of 279 papers contained pre-defined author keywords corresponding with sustainable entrepreneurship domain. The analysis of co-occurrence of keywords was performed using VOSviewer software. The details are included in [38].

This data analysis also attempts to incorporate a great amount of information about these SE factors and, therefore, is far more comprehensive in its detail than the source resources. Consequently, the proposed ontology allows to acquisition, representation, and manipulation of sustainable enterprise knowledge and remoulds it into sustainable-driven entrepreneurship as well as structuring and organising libraries of knowledge. The exploited data set on base of the bibliometric analysis [38] provided the literature-based set of factors in the informal level, which, in the aftermath of this, being encoded into formal ontological representation. The network visualization is attached in Figure 3.

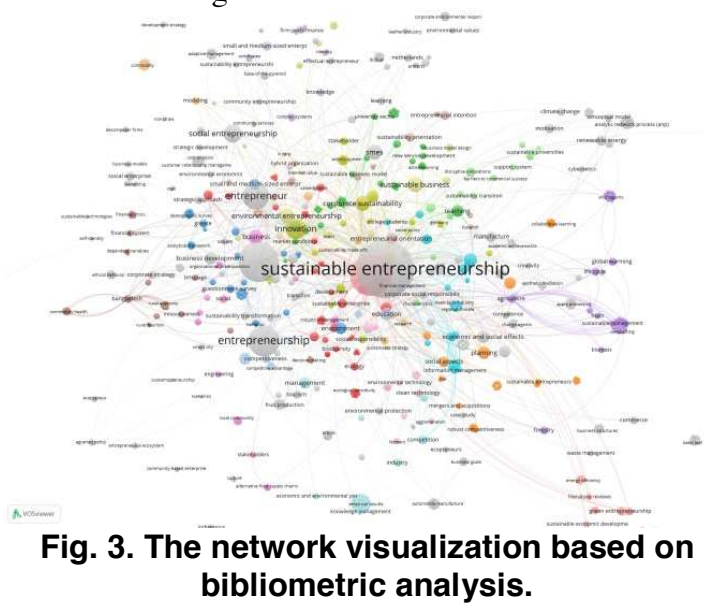

\subsection{Knowledge coding and ontology construction}

To emphasize the role of the ontology in EO model, its purpose is to serve as the basis for more specific corporate models that represent a shared understanding of the organization [30], [37]. From a technical point of view, ontology offers stable basis for specifying software requirements, however, the stability of the model should be determined by the important factors and issues for businesses [11]. To extend the usability of ontology, formalizing of the EO, as well as using Description Logic, allows more precise determination of the meaning of terms than is possible in natural language. A resulting benefit is the possibility of greater consistency and completeness, what ensures that terms are used in a consistent way and properly encoded [20], [24], [26].

The in-depth bibliometric analysis allowed extracting all the concepts from previously defined set of criteria and sub-criteria, and in the aftermath of this, defining properties and relations between them to form the backbone of the ontology. The factors and definitions need to be coded from informal into formal statements. The condensed immense amount of information allowed constructing ontology-based model as a classification schema of sustainable entrepreneurship factors as well as a tool performing 
knowledge from being machine-readable to machineunderstandable. The codified knowledge will help in the sustainable enterprise modelling domain, serving a stable basis for specifying sustainable requirements. Therefore, the proposed ontology aims to convert the informal version of Enterprise Ontology and SE factors dedicated to the SE domain, expressed in natural language, into the formal language. The proposed ontology was expressed using Ontology Web Language (OWL) standard and implemented in Protégé environment. The formalization and classification of selected SE factors is provided in related document: Extended Appendix and Data for Ontology-based Model for Sustainable Entrepreneurship Domain [34] in section 3.1.5. (see: table 3 ). It provides the defined and knowledge-based set of criteria and sub-criteria containing relevant factors, important for the sustainable enterprise. Overall, the ontology contains 3 main classes at the 1st level, 10 sub-classes at the 2 nd level, 129 sub-classes at the 3rd level and 79 sub-classes at the 4th level. In addition, 31 sets of factors have been assigned to the Set Name class. Class owl: Thing is the super-class for all classes in each ontology. To sum up, the implemented ontology comprises 252 primitive classes. Primitive classes represent a group of classes which has only the necessary conditions.

Figure 4 shows the main classes and sub-classes with assigned relations and determined domain and range.

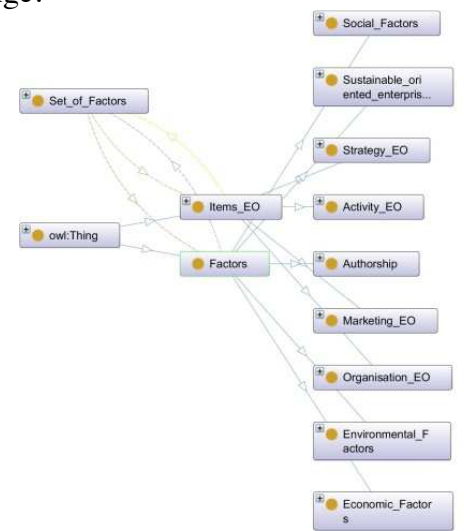

Fig. 4. The main classes and sub-classes with assigned relations and determined domain and range.

The process of collection, and further categorization, the information of the SE factors performed the knowledge from the unstructured form into semi-structured. This part was documented using the mathematical background of the set theory. Further, this was a basis to provide a formal description of the domain knowledge. For this purpose, on base of the specific characteristics of the presented above sets of factors, the mathematical description is shown in Table 1.

Table 1. The formalization and classification of selected SE factors.

\begin{tabular}{|c|c|}
\hline Description & Definition \\
\hline $\begin{array}{l}\text { In the domain and range of a relation, if } \\
\mathrm{R} \text { is a relation from set } \mathrm{S} \text { and } \mathrm{F} \text {, then the } \\
\text { set of all taxons (all of the first } \\
\text { components of the ordered pairs) } \\
\text { belonging to } \mathrm{R} \text { is called the domain of } \\
\mathrm{R} \text {. }\end{array}$ & $\begin{array}{l}R=\{s \in S:(s, f) \in R \text { for some } f \in \\
F\}\end{array}$ \\
\hline $\begin{array}{l}\text { The set of all second components of the } \\
\text { ordered pairs (the set of all taxons) } \\
\text { belonging to } R \text { is called the range of } R \text {. }\end{array}$ & $\begin{array}{l}R=\{f \in F:(t x, f) \in R \text { for some } t x \\
\in T\}\end{array}$ \\
\hline $\begin{array}{l}\text { If set of factors } S \text { and factors } F \text { are two } \\
\text { non-empty sets, then the Cartesian } \\
\text { product } T \text { of } S \text { and } F \text {, denoted } S \times F \text {, is } \\
\text { the set of all ordered pairs (s, f) such that } \\
s \in S \text { and } f \in F \text {. }\end{array}$ & $S \times F=\{(s, f): s \in S, f \in F\}$ \\
\hline $\begin{array}{l}\text { Factors F contain the finite set of taxons, } \\
\text { defined as follows: E represents } \\
\text { Environmental, SC defines Social, EC } \\
\text { shows Economic and SOE refers to } \\
\text { Sustainable-oriented enterprises. }\end{array}$ & $\mathrm{F}=\{\mathrm{E}, \mathrm{SC}, \mathrm{EC}, \mathrm{SOE}\}$ \\
\hline $\begin{array}{l}\text { Set of factors S contains the finite set of } \\
\text { taxons, which are subsets numbered } \\
\text { from S1 to S31, containing the specified } \\
\text { abilities determining SE. }\end{array}$ & $\begin{array}{l}\mathrm{S}=\{\mathrm{S} 1, \mathrm{~S} 2, \mathrm{~S} 3, \mathrm{~S} 4, \mathrm{~S} 5, \mathrm{~S} 6, \mathrm{~S} 7, \\
\mathrm{S} 8, \mathrm{~S} 9, \mathrm{~S} 10, \mathrm{~S} 11, \mathrm{~S} 12, \mathrm{~S} 13, \mathrm{~S} 14, \\
\mathrm{~S} 15, \mathrm{~S} 16, \mathrm{~S} 17, \mathrm{~S} 18, \mathrm{~S} 19, \mathrm{~S} 20, \\
\mathrm{~S} 21, \mathrm{~S} 22, \mathrm{~S} 23, \mathrm{~S} 24, \mathrm{~S} 25, \mathrm{~S} 26, \\
\mathrm{~S} 27, \mathrm{~S} 28, \mathrm{~S} 29, \mathrm{~S} 30, \mathrm{~S} 31\}\end{array}$ \\
\hline $\begin{array}{l}\text { E is defined as a separated set of } \\
\text { Environmental, where EV defines } \\
\text { Environmental protection, RM } \\
\text { determines Resources management and } \\
\text { EVD covers Environmental dimension. }\end{array}$ & $\mathrm{E}=\{\mathrm{EV}, \mathrm{RM}, \mathrm{EVD}\}$ \\
\hline $\begin{array}{l}\text { SC represents a separated set of Social, } \\
\text { where SD refers to Social dimension, } \\
\text { SOP means Social-oriented policy and } \\
\text { EDM covers Ethical decision-making. }\end{array}$ & $\mathrm{SC}=\{\mathrm{SD}, \mathrm{SOP}, \mathrm{EDM}\}$ \\
\hline $\begin{array}{l}\text { EC refers to one-element set of } \\
\text { Economic, where ED represents } \\
\text { Economic dimension. }\end{array}$ & $\mathrm{EC}=\{\mathrm{ED}\}$ \\
\hline $\begin{array}{l}\text { SOE is defined as a separated set of } \\
\text { Sustainable-oriented enterprises, where } \\
\text { MS defines Market strategy, SM covers } \\
\text { Sustainability management, SCB } \\
\text { presents Sustainable advantage/capacity } \\
\text { building, SG refers to Sustainable goal, } \\
\text { VA means Value added and CDO shows } \\
\text { Creating development opportunities. }\end{array}$ & $\begin{array}{l}\mathrm{SOE}=\{\mathrm{MS}, \mathrm{SM}, \mathrm{SCB}, \mathrm{SG}, \mathrm{VA}, \\
\mathrm{CDO}\}\end{array}$ \\
\hline $\begin{array}{l}\text { EV represents a set of Environmental } \\
\text { protection, where EVs presents } \\
\text { Environmental stability, EVpp defines } \\
\text { Pollution protection, EVrr determines } \\
\text { Recycling, re-use and EVp covers } \\
\text { Environmental-friendly production. }\end{array}$ & $E V=\{E V s, E V p p, E V r r, E V p\}$ \\
\hline $\begin{array}{l}\text { RM represents Resources management } \\
\text { and contains a finite set of taxons: } \\
\text { RMprm shows Product resource } \\
\text { management and RMem covers Energy } \\
\text { management. }\end{array}$ & $\mathrm{RM}=\{\mathrm{RMprm}, \mathrm{RMem}\}$ \\
\hline $\begin{array}{l}\text { EVD determines Environmental } \\
\text { dimension, where EVDee means Eco- } \\
\text { efficiency and EVDa shows } \\
\text { Environmental-oriented aspects. }\end{array}$ & $\mathrm{EVD}=\{$ EVDee, $\mathrm{EVDa}\}$ \\
\hline $\begin{array}{l}\text { SD covers Social dimension, where SDa } \\
\text { presents Social aspects, SDd displays } \\
\text { Donations, SDsp means Social support } \\
\text { and SDse introduces Socio-efficiency. }\end{array}$ & $\mathrm{SD}=\{\mathrm{SDa}, \mathrm{SDd}, \mathrm{SDsp}, \mathrm{SDse}\}$ \\
\hline
\end{tabular}




\begin{tabular}{|c|c|}
\hline $\begin{array}{l}\text { Social-oriented policy SOP contains a } \\
\text { finite set of taxons, where SOPhr } \\
\text { represents Human resources, SOPia } \\
\text { covers Institutional aspects, SOPoc } \\
\text { represents Organizational culture, } \\
\text { SOPess shows Employee satisfaction } \\
\text { support, SOPd means Demographic and } \\
\text { SOPr displays Relationships. }\end{array}$ & $\begin{array}{l}\text { SOP }=\{\text { SOPhr, SOPia, SOPoc, } \\
\text { SOPess, SOPd, SOPr }\}\end{array}$ \\
\hline $\begin{array}{l}\text { Let EDM represent Ethical decision- } \\
\text { making, where EDMsve presents Shared } \\
\text { value \& ethics, EDMqt displays Quality } \\
\& \text { trust and EDMe covers Equity. }\end{array}$ & $\begin{array}{l}\mathrm{EDM}=\{\text { EDMsve, EDMqt, } \\
\mathrm{EDMe}\}\end{array}$ \\
\hline $\begin{array}{l}\text { Let ED be Economic dimension, where } \\
\text { the following abbreviations are used: } \\
\text { EDrm represents Risk management, } \\
\text { EDvc refers to Value creation, EDe } \\
\text { shows Evaluation and EDa covers } \\
\text { Economic aspects. }\end{array}$ & $\mathrm{ED}=\{\mathrm{EDrm}, \mathrm{EDvc}, \mathrm{EDe}, \mathrm{EDa}\}$ \\
\hline $\begin{array}{l}\text { MS represents Market strategy, where } \\
\text { MSsmo covers Sustainable market } \\
\text { orientation, MSss shows Sustainable } \\
\text { strategy, MSsm displays Strategy \& } \\
\text { management, and MSrm defines Risk } \\
\text { management. }\end{array}$ & $\begin{array}{l}\text { MS }=\{\text { MSsmo, MSss, MSsm, } \\
\text { MSrm }\}\end{array}$ \\
\hline $\begin{array}{l}\text { SM determines Sustainability } \\
\text { management, where SMswc is used to } \\
\text { represent Sustainable wealth creation, } \\
\text { SMss covers Sustainable strategy and } \\
\text { SMsd displays Contribution to } \\
\text { sustainability development. }\end{array}$ & $\mathrm{SM}=\{$ SMswc, SMss, SMsd $\}$ \\
\hline $\begin{array}{l}\text { SCB defines } \\
\text { Sustainable } \\
\text { advantage/capacity building, where } \\
\text { SCBa means Competitive } \\
\text { intelligence/advantage, SCBc presents } \\
\text { Competences and SCBsd refers to } \\
\text { Contribution to sustainability } \\
\text { development. }\end{array}$ & $\mathrm{SCB}=\{\mathrm{SCBa}, \mathrm{SCBc}, \mathrm{SCBsd}\}$ \\
\hline $\begin{array}{l}\text { Let SG define Sustainable goal, where } \\
\text { SG3P defines 3P and SGswc represents } \\
\text { Sustainable wealth creation. }\end{array}$ & $\mathrm{SG}=\{\mathrm{SG} 3 \mathrm{P}, \mathrm{SGswc}\}$ \\
\hline $\begin{array}{l}\text { VA presents Value added, where VAswc } \\
\text { refers to Sustainable wealth creation, } \\
\text { VAvc determines Value creation, VAk } \\
\text { covers Knowledge and VAi defines } \\
\text { Innovation. }\end{array}$ & $\begin{array}{l}\mathrm{VA}=\{\mathrm{VAswc}, \mathrm{VAvc}, \mathrm{VAk}, \\
\mathrm{VAi}\}\end{array}$ \\
\hline $\begin{array}{l}\text { Let CDO present Creating development } \\
\text { opportunities, where CDOd means } \\
\text { Development, CDOco represents } \\
\text { Creating opportunities, CDOi refers to } \\
\text { Innovation, CDOcc determines } \\
\text { Cooperation/collaboration, CDOch } \\
\text { shows Change, CDO3P determines 3P } \\
\text { and CDOin displays Integration. }\end{array}$ & $\begin{array}{l}\mathrm{CDO}=\{\mathrm{CDOd}, \mathrm{CDOco}, \mathrm{CDO}, \\
\text { CDOcc, } \quad \text { CDOch, CDO3P, } \\
\text { CDOin }\}\end{array}$ \\
\hline
\end{tabular}

Based on the conducted bibliometric analysis presented in details in [38] and the provided formalization and classification of selected SE factors (Table 1), the taxonomy schema of elaborated sets of factors was elaborated. This analysis contains the set of factors and abilities dedicated to sustainability domain. Based on this, the 31 papers were selected for further elaboration. They are characterized by different sets of factors. The aim of the analysis is to provide attributes and criteria and indicate the various areas of its application, defined as following main factors: social, economic, environmental or sustainable-oriented entrepreneurship. Table 3 intends to depict the set of factors and sub-factors on the 1st, 2nd and 3rd level. Each of analyzed groups is specified by the assigned factors which are consistent for each group of analyzed sets, whereas the set of factors is shown in the columns and numbered from $\mathrm{S} 1$ to $\mathrm{S} 31$

The full size version of taxonomy is provided in Extended Appendix and Data for Ontology-based Model for Sustainable Entrepreneurship Domain [34] in section 3.1.5. Documentation in Table 3 [38]. Due to the fact that that SE domain is still developing, and the set of criteria was based on in-depth bibliometric analysis, it is clear that the proposed ontology needs to be improved and updated. Enhancing this process, the source code (OWL/XML) is publicly available and it is provided https://webprotege.stanford.edu/\#projects/46851f3e149a-4433-8cff-c8d0d6ff5e68. The source code as well as the formal description using Description Logic is attached in supplementary files.

\section{Table 3. The taxonomy schema of elaborated} sets of factors.

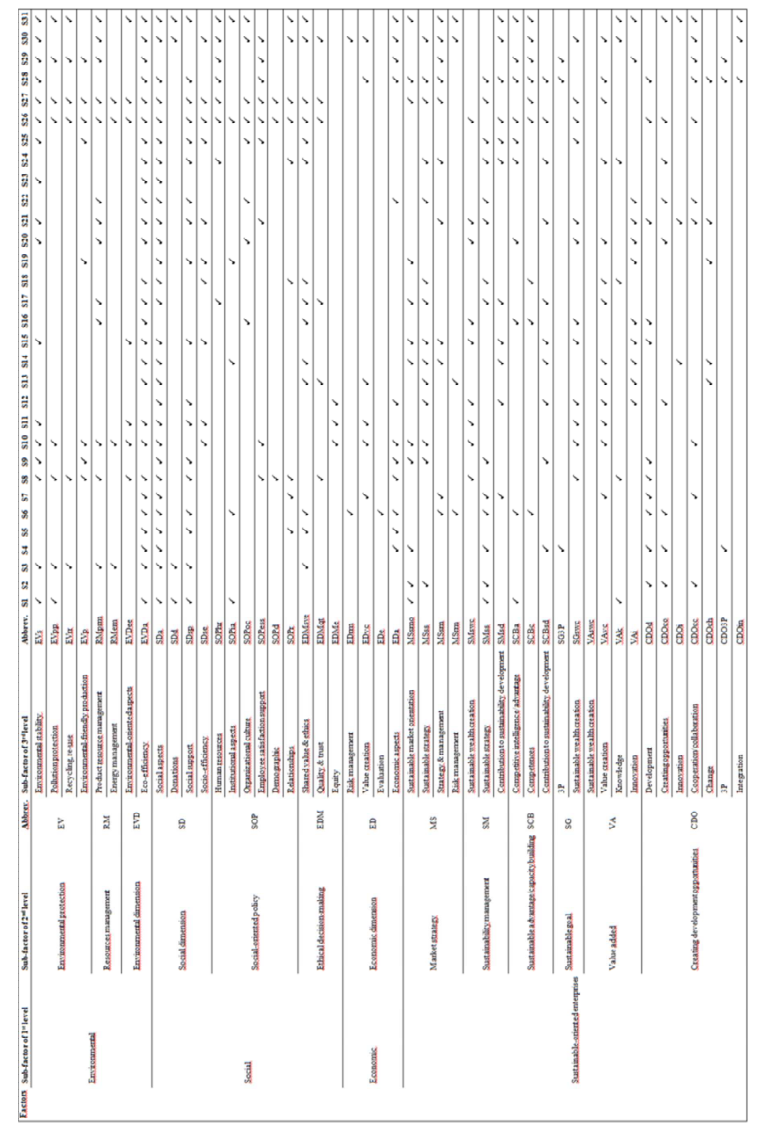




\subsection{Validating of ontology-based model for SE domain}

The ontology contains both SE factors and EO terms and definitions. Collecting and combining the knowledge both of SE and EO in one place supports the operational access to the distinguished factors among various users (e.g. stakeholders, collaborators, organizations, suppliers and employees). Hence, this ontology is designed to determine SE factors which can help decision makers to determine and prioritize suitable strategies/scenarios. In this context, the sets of exemplary profiles and scenarios/strategies are defined. In SE domain multiple factors collected on various levels of details are demarcated. The sample scenarios and strategies are worked out and implemented in the ontology (Table 1) and fully described in Extended Appendix and Data for Ontology-based Model for Sustainable Entrepreneurship Domain [34].

Table 1. Sustainable-oriented strategies for enterprises - case studies.

\begin{tabular}{|c|c|c|}
\hline $\begin{array}{ll}\begin{array}{l}\text { Overall } \\
\text { strategy }\end{array} & \text { goal/SE } \\
\end{array}$ & Goal & Objective \\
\hline $\begin{array}{l}\text { Empower } \\
\text { stakeholders/collabo } \\
\text { rators to actively } \\
\text { participate in } \\
\text { innovation planning. }\end{array}$ & $\begin{array}{l}\text { Improve the } \\
\text { innovative } \\
\text { collaboration and } \\
\text { detect innovation } \\
\text { opportunities. }\end{array}$ & $\begin{array}{l}\text { Increase creating of } \\
\text { development; opportunities } \\
\text { based on innovation. } \\
\text { Increase value added having } \\
\text { innovation. }\end{array}$ \\
\hline $\begin{array}{l}\text { Empower } \\
\text { stakeholders/collabo } \\
\text { rators to protect } \\
\text { social aspects. }\end{array}$ & $\begin{array}{l}\text { Implementing and } \\
\text { enhancing social } \\
\text { aspects. }\end{array}$ & $\begin{array}{l}\text { Protect ethical decision making } \\
\text { respecting shared value and } \\
\text { ethics, equity and quality and } \\
\text { trust. } \\
\text { Protect social aspects by } \\
\text { offering social support and } \\
\text { socio-efficiency. }\end{array}$ \\
\hline $\begin{array}{l}\text { Policy and activities } \\
\text { aimed at sustainable } \\
\text { wealth creation. }\end{array}$ & $\begin{array}{l}\text { Implementation } \\
\text { sustainable } \\
\text { wealth creation } \\
\text { strategy and make } \\
\text { use of means for } \\
\text { reaching } \\
\text { sustainable goals } \\
\text { and management. }\end{array}$ & $\begin{array}{l}\text { Focus on building sustainable } \\
\text { wealth creation by reaching } \\
\text { sustainable goals. } \\
\text { Focus on building sustainable } \\
\text { wealth creation by performing } \\
\text { sustainable management and } \\
\text { value added. }\end{array}$ \\
\hline $\begin{array}{l}\text { Preventive and } \\
\text { environmental } \\
\text { protection activities. }\end{array}$ & $\begin{array}{l}\text { Implementation } \\
\text { of activities } \\
\text { related to } \\
\text { environmental } \\
\text { policy and } \\
\text { awareness. }\end{array}$ & $\begin{array}{l}\text { Ensure environmental friendly } \\
\text { production and environmental } \\
\text { stability. } \\
\text { Taking care of protection } \\
\text { against pollution. } \\
\text { Offer recycling and re use. }\end{array}$ \\
\hline
\end{tabular}

For example, an enterprise is searching for innovation opportunities. The result of usage of the constructed ontology is to provide complete set of factors with regard of innovation achievement. Collected knowledge provided the most general factors and also specific ones, influencing on innovation processes. It is assumed that the set of criteria should include the factors such as creating development opportunities, which include innovation, and also value added having innovation. The innovative actions can be encouraged by knowledge, therefore this factor was also considered in this process. As a result, final set contains potential factors related to innovation.
Defining the necessary and sufficient conditions, and afterwards implementing it into the Protégé software permits on starting the reasoning process. The set of results is shown on Fig. 5.

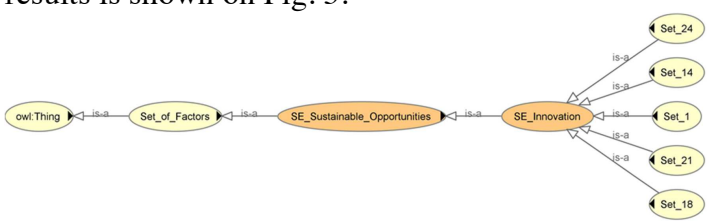

Fig. 5. Innovation factors - case study.

The constructed definition (also named as defined class) is displayed using the orange color whereas the yellow color displays the primitive classes. The class hierarchy is portrayed by arrow directions. The most located class on the left side, the higher hierarchy. A backbone of the ontology in hierarchical form is also determined by IS-A relations. In accordance with the constructed definition, only 5 sets of factors match these requirements.

Focusing on aspects of environmental protection, it is necessary to consider the following factors related to environment protection in a form of environmental friendly production and environmental stability, and also pollution protection and offering recycling and re use. Implementation of activities related to environmental policy and awareness is a key task for sustainable enterprise. In this case the set of activities may vary depending on the nature of the conducted business. However, the factors indicated appear to be general to most of them. The reasoning process finished successfully, providing a set of results as shown on Fig. 6.

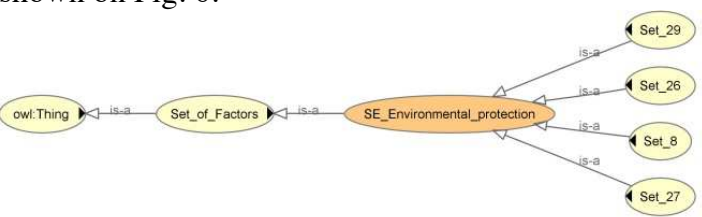

Fig. 6. Environmental protection - case study.

The other defined queries were included in Extended Appendix and Data for Ontology-based Model for Sustainable Entrepreneurship Domain [34] in section 3.1 .4 (Fig. 8 and Fig. 9). It is possible to create any number of queries based on the available set of factors.

\subsection{The analysis of research results}

The ontology-based model proposed in this paper covers the broad field of sustainable entrepreneurship, including selective factors expanded in [38] and artefacts of EO elaborated in [31], which undoubtedly gives a comprehensive picture of domain modeling. Through this two-part ontology, it is expected that the 
implementation of innovative sustainability strategies and modeling approaches in many perspectives will increase value creation and further develop sustainable development. The completeness of the model was verified on the basis of objective and complete sources of data, and the correctness of the created knowledge model was confirmed in the conducted case studies illustrating the selected SE strategies. Responding to the research questions: how enterprises can run a business and implement SDG and which factors can support or constrain SE, a knowledge-based approach to linking sustainable enterprise factors with the contribution of knowledge management was implemented. This model contained the exemplary sustainable strategies which were considered in this paper to present the abilities of the proposed solution. Following this approach, it was possible to obtain an overview of SE factors and abilities, highlighting the opportunities regarding the sustainable development.

\section{Conclusions}

The aim of this paper was to presents a knowledge-based approach to linking sustainable enterprise factors with the contribution of knowledge management. Due to the fact that the recognition and implementation of sustainable development opportunities are more complex for the entrepreneur than the recognition of non-sustainable opportunities, the condensed immense amount of information were analyzed and exploited to construct ontology-based model. This model offered a classification schema of SE factors as well as a tool performing knowledge from being machine-readable to machineunderstandable. The codified knowledge may help in the sustainable enterprise modelling domain, serving a stable basis for specifying sustainable requirements. As a consequence, this paper provides both practical and theoretical implications for SE domain. On the one hand, a tool is provided in the form of an ontological knowledge model, enabling machine reading of data and handling knowledge in SE domain, and on the other hand, the formalization and grouping of factors in the field of SE is performed. This work also aims to promote SE and strengthen businesses to contribute to the achievement of the SDG offering the dedicated tool to ensure transparency of existing factors, abilities and relations, and to align sustainable development strategies in a given enterprise. To test the proposed model, the exemplary sustainable strategies were considered in this paper and in the related supplementary file: Extended Appendix and Data for Ontology-based Model for Sustainable Entrepreneurship Domain [34].
Due to the dynamic development of technologies new types of sustainable enterprise models are envisioned, hence, to be adaptive, existing enterprise models must make appropriate usage of technical features. Therefore, for this purpose, the proposed ontology-based model must be managed appropriately to enable reuse, extension and refinement within an enterprise and to collaborate with dissimilar models and systems. To be able to adapt and react to the changes, the OWL and DL provides common standard of description and formal logics to guarantee machinereadability.

\section{References}

[1] P. Sarango-Lalangui, J. Santos, and E. Hormiga, 'The Development of Sustainable Entrepreneurship Research Field', Sustainability, vol. 10, no. 6, p. 2005, Jun. 2018, doi: $10.3390 /$ su10062005.

[2] F. Figge, T. Hahn, S. Schaltegger, and M. Wagner, 'The Sustainability Balanced Scorecard - linking sustainability management to business strategy', Bus. Strategy Environ., vol. 11, no. 5, pp. 269-284, Sep. 2002, doi: 10.1002/bse.339.

[3] A. C. Baresel-Bofinger, P. H. Ketikidis, S. L. Koh, and J. Cullen, 'Role of 'green knowledge'in the environmental transformation of the supply chain: the case of Greek manufacturing', Int. J. Knowl-Based Dev., vol. 2, no. 1, pp. 107-128, 2011.

[4] D. A. Shepherd and H. Patzelt, 'The new field of sustainable entrepreneurship: Studying entrepreneurial action linking "what is to be sustained" with "what is to be developed", Entrep. Theory Pract., vol. 35, no. 1, pp. 137-163, 2011.

[5] M. Peruzzini, F. Gregori, A. Luzi, M. Mengarelli, and M. Germani, 'A social life cycle assessment methodology for smart manufacturing: The case of study of a kitchen sink', J. Ind. Inf. Integr., vol. 7, pp. 24-32, Sep. 2017, doi: 10.1016/j.jii.2017.04.001.

[6] S. Schaltegger and M. Wagner, 'Sustainable entrepreneurship and sustainability innovation: categories and interactions', Bus. Strategy Environ., vol. 20, no. 4, pp. 222-237, 2011.

[7] H. Patzelt and D. A. Shepherd, 'Recognizing Opportunities for Sustainable Development', Entrep. Theory Pract., vol. 35, no. 4, pp. 631-652, Jul. 2011, doi: $10.1111 / \mathrm{j} .1540-6520.2010 .00386 . x$.

[8] C. Volkmann, K. Fichter, M. Klofsten, and D. B. Audretsch, 'Sustainable entrepreneurial ecosystems: an emerging field of research', Small Bus. Econ., vol. 56, no. 3, pp. 1047-1055, Feb. 2021, doi: 10.1007/s11187019-00253-7.

[9] W. Kanda, O. Hjelm, J. Clausen, and D. Bienkowska, 'Roles of intermediaries in supporting eco-innovation', J. Clean. Prod., vol. 205, pp. 1006-1016, Dec. 2018, doi: 10.1016/j.jclepro.2018.09.132.

[10] J. L. G. Dietz, 'Enterprise Ontology - Understanding The Essence Of Organizational Operation', in Enterprise Information Systems VII, C.-S. Chen, J. 
Filipe, I. Seruca, and J. Cordeiro, Eds. Dordrecht: Springer Netherlands, 2006, pp. 19-30. doi: 10.1007/978-1-4020-5347-4_3.

[11] S. S. Rao and A. Nayak, 'Enterprise Ontology Model For Tacit Knowledge Externalization In SocioTechnical Enterprises.', Interdiscip. J. Inf. Knowl. Manag., vol. 12, 2017.

[12] E. Blomqvist and A. Öhgren, 'Constructing an enterprise ontology for an automotive supplier', Eng. Appl. Artif. Intell., vol. 21, no. 3, pp. 386-397, Apr. 2008, doi: 10.1016/j.engappai .2007.09.004.

[13] E. Muñoz, E. Capon-Garcia, J. Lainez, A. Espuña, and L. Puigjaner, 'Ontological framework for the enterprise from a process perspective', 2011, pp. 538-546.

[14] F. Lüdeke-Freund, 'Sustainable entrepreneurship, innovation, and business models: Integrative framework and propositions for future research', Bus. Strategy Environ., vol. 29, no. 2, pp. 665-681, Feb. 2020, doi: 10.1002/bse.2396.

[15] E. Terán-Yépez, G. M. Marín-Carrillo, M. del P. Casado-Belmonte, and M. de las M. CapobiancoUriarte, 'Sustainable entrepreneurship: Review of its evolution and new trends', J. Clean. Prod., vol. 252, p. 119742, Apr. 2020, doi: 10.1016/j.jclepro.2019.119742.

[16] S. Batra, 'Sustainable entrepreneurship and knowledge based development', 2012, pp. 2-30.

[17] H. Hummels and A. Argyrou, 'Planetary demands: Redefining sustainable development and sustainable entrepreneurship', J. Clean. Prod., vol. 278, p. 123804 , Jan. 2021, doi: 10.1016/j.jclepro.2020.123804.

[18] M. Moradi and B. Vallespir, 'Knowledge Management And Enterprise Modelling: A Complementary View', IFAC Proc. Vol., vol. 40, no. 18, pp. 67-72, Sep. 2007, doi: 10.3182/20070927-4-RO-3905.00013.

[19] G. Weichhart, C. Stary, and F. Vernadat, 'Enterprise modelling for interoperable and knowledge-based enterprises', Int. J. Prod. Res., vol. 56, no. 8, pp. 2818 2840, Apr. 2018, doi: 10.1080/00207543.2017.1406673.

[20] D. Kang, J. Lee, S. Choi, and K. Kim, 'An ontologybased Enterprise Architecture', Expert Syst. Appl., vol. 37, no. 2, pp. 1456-1464, Mar. 2010, doi: 10.1016/j.eswa.2009.06.073.

[21] Konys, 'Green Supplier Selection Criteria: From a Literature Review to a Comprehensive Knowledge Base', Sustainability, vol. 11, no. 15, p. 4208, Aug. 2019, doi: 10.3390/su11154208.

[22] S. Kraines, R. Batres, B. Kemper, M. Koyama, and V. Wolowski, 'Internet-Based Integrated Environmental Assessment, Part II: Semantic Searching Based on Ontologies and Agent Systems for Knowledge Discovery', J. Ind. Ecol., vol. 10, no. 4, pp. 37-60, Feb. 2008, doi: 10.1162/jiec.2006.10.4.37.

[23] N. Oertwig, R. Jochem, and T. Knothe, 'Sustainability in Model-based Planning and Control of Global Value Creation Networks', Procedia Manuf., vol. 8, pp. 183190, 2017, doi: 10.1016/j.promfg.2017.02.023.

[24] E. Muñoz, E. Capón-García, J. M. Laínez, A. Espuña, and L. Puigjaner, 'Considering environmental assessment in an ontological framework for enterprise sustainability', J. Clean. Prod., vol. 47, pp. 149-164, May 2013, doi: 10.1016/j.jclepro.2012.11.032.

[25] F. Vernadat, 'Enterprise modelling: Research review and outlook', Comput. Ind., vol. 122, p. 103265, Nov. 2020, doi: 10.1016/j.compind.2020.103265.

[26] V. W. B. Martins, I. S. Rampasso, R. Anholon, O. L. G. Quelhas, and W. Leal Filho, 'Knowledge management in the context of sustainability: Literature review and opportunities for future research', J. Clean. Prod., vol. 229, pp. 489-500, Aug. 2019, doi: 10.1016/j.jclepro.2019.04.354

[27] S. Liu, J. Moizer, P. Megicks, D. Kasturiratne, and U. Jayawickrama, 'A knowledge chain management framework to support integrated decisions in global supply chains', Prod. Plan. Control, vol. 25, no. 8, pp. 639-649, 2014.

[28] A. A. Khan and S. A. Khader, 'An approach for externalization of expert tacit knowledge using a query management system in an e-learning environment', Int . Rev. Res. Open Distrib. Learn., vol. 15, no. 6, Oct. 2014, doi: 10.19173/irrodl.v15i6.1935.

[29] T. R. Gruber, 'A translation approach to portable ontology specifications', Knowl. Acquis., vol. 5, no. 2, pp. 199-220, Jun. 1993, doi: 10.1006/knac.1993.1008.

[30] J. L. G. Dietz and H. B. F. Mulder, 'Introduction to Enterprise Engineering', in Enterprise Ontology, Cham: Springer International Publishing, 2020, pp. 9-12. doi: 10.1007/978-3-030-38854-6_2.

[31] M. Uschold, M. King, S. Moralee, and Y. Zorgios, 'The Enterprise Ontology', Knowl. Eng. Rev., vol. 13, no. 1, pp. 31-89, Mar. 1998, doi: $10.1017 / \mathrm{S} 0269888998001088$.

[32] M. Uschold, 'Knowledge level modelling: concepts and terminology', Knowl. Eng. Rev., vol. 13, no. 1, pp. 5-29, Mar. 1998, doi: 10.1017/S0269888998001040.

[33] Z. Rajabi, B. Minaei, and M. A. Seyyedi, 'Enterprise Architecture Development Based on Enterprise Ontology', J. Theor. Appl. Electron. Commer. Res., vol. 8, no. 2, pp. 13-14, 2013, doi: 10.4067/S071818762013000200007.

[34] Konys A., 'Extended Appendix and Data for Ontologybased Model for Sustainable Entrepreneurship Domain', Supplementary File, 2021.

[35] T. Suga and J. Iijima, 'Algebra for Enterprise Ontology: towards analysis and synthesis of enterprise models', Enterp. Inf. Syst., vol. 12, no. 3, pp. 341-370, Mar. 2018, doi: 10.1080/17517575.2017.1367962.

[36] A. Konys, 'An Ontology-Based Knowledge Modelling for a Sustainability Assessment Domain', Sustainability, vol. 10, no. 2, p. 300, Jan. 2018, doi: $10.3390 /$ su10020300

[37] S. Chelbi and N. Taleb, 'The use of Ontologies for Enterprise Modeling and Evaluation', in 2020 2nd International Conference on Mathematics and Information Technology (ICMIT), Adrar, Algeria, Feb. 2020, pp. 175-179. doi: 10.1109/ICMIT47780.2020.9047039.

[38] A. Konys, 'Towards Sustainable Entrepreneurship Holistic Construct', Sustainability, vol. 11, no. 23, p. 6749, Nov. 2019, doi: 10.3390/su11236749. 